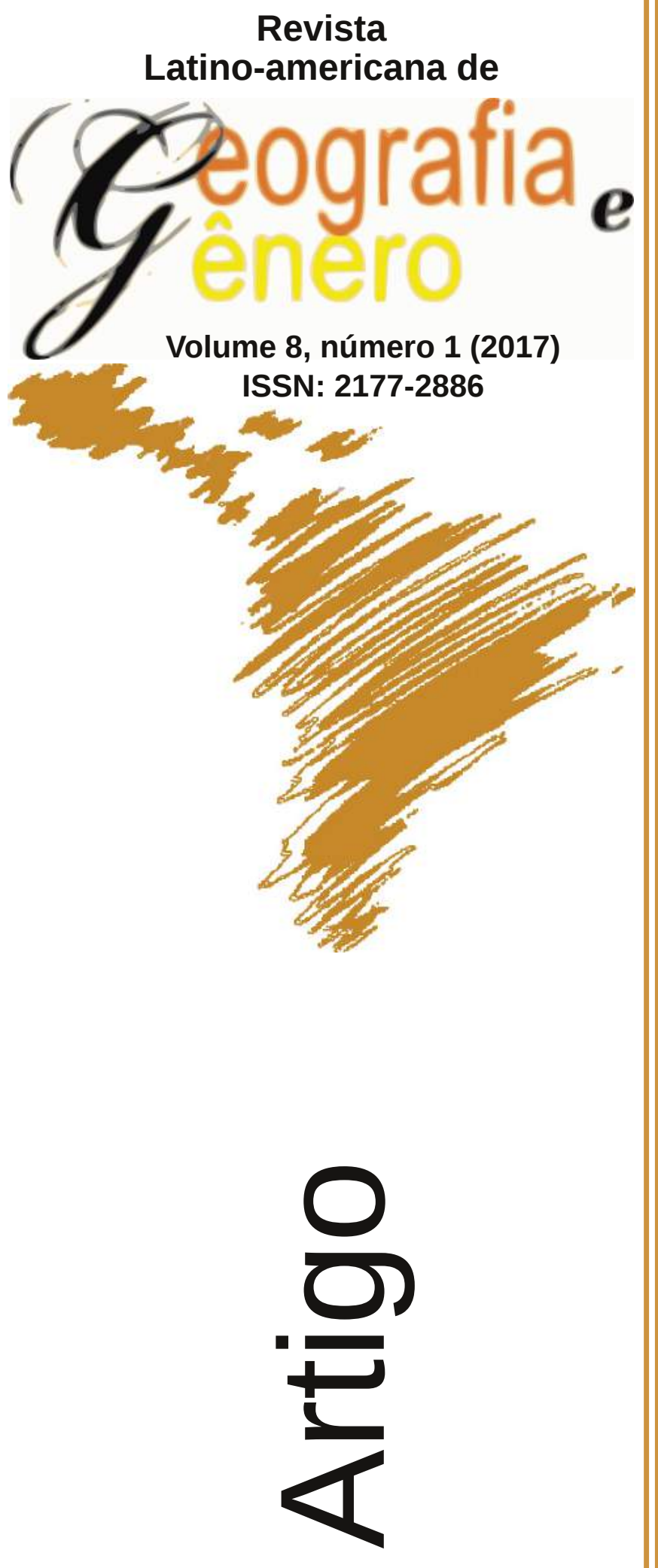

'Longe de Chanel ou Pitanguy Existem Corpos Desejados Aquil: Diálogos Queer Sobre os Corpos (Tra)Vestidos de Desejos nas Prisões

'Longe de Chanel ou Pitanguy Existem Corpos Desejados Aqui': Diálogos Queer Sobre los Cuerpos (Tra)Vestidos de Deseos en las Cárceles

'Far Away From Chanel or Pitanguy There are Desirable Bodies in Here': A Queer Dialogue on Bodies (Cross)Dressed in Desire in Prisons

Bárbara Cossettin Costa Beber Brunini Universidade Paranaense - Brasil barbrunini@unipar.br

Wiliam Siqueira Peres Universidade Estadual Paulista - Brasil barbrunini@unipar.br

Rogério Amador de Melo

Universidade Paranaense - Brasil barbrunini@unipar.br

Como citar este artigo:

BRUNINI, Bárbara Cossettin Costa Beber; PERES, Wiliam Siqueira; MELO, Rogério Amador de. 'Longe de Chanel ou Pitanguy Existem Corpos Desejados Aqui': Diálogos Queer Sobre os Corpos (Tra)Vestidos de Desejos nas Prisões. Revista Latino Americana de Geografia e Gênero, v. 8, n. 1, p. 368-384, 2017. ISSN 2177-2886.

Disponível em:

http://www.revistas2.uepg.br/index.php/rlagg 


\title{
'Longe de Chanel ou Pitanguy Existem Corpos Desejados Aqui': Diálogos Queer Sobre os Corpos (Tra)Vestidos de Desejos nas Prisões
}

\author{
'Longe de Chanel ou Pitanguy Existem Corpos Desejados Aqui': Diálogos \\ Queer Sobre los Cuerpos (Tra)Vestidos de Deseos en las Cárceles
}

\section{'Far Away From Chanel or Pitanguy There are Desirable Bodies in Here': A Queer Dialogue on Bodies (Cross)Dressed in Desire in Prisons}

\begin{abstract}
Resumo
Apresentar a perspectiva Queer é agir de maneira provocativa e desafiante, ainda mais quando nós, agentes atuantes em ambiente penal e profissionais da psicologia, somos atravessados pela sua força impetuosa e sagaz. Os corpos travestidos de sujeitos localizados no sistema prisional e estigmatizados como corpos perversos ou obscenos por outros encarcerados são julgados pelos prazeres sentido na carne. As travestis no sistema prisional emergem enquanto corpos já julgados e passíveis ao castigo da lei. Contudo, reinauguram novas formas de existir em um contexto diferente, regido pela instituição prisional possibilitando outras formas de sentir, pensar, desejar, agir e viver. Apresentamos aqui, de modo crítico, as conversações propostas pela perspectiva Queer descritas em diversas fontes bibliográficas oportunizando novos questionamentos e debates sobre o olhar pela/da diferença.
\end{abstract}

Palavras-Chave: Psicologia; Travestis; Sistema Prisional.

\section{Resumen}

Presentar la perspectiva Queer es actuar de manera provocativa y desafiante, sobre todo cuando nosotros, agentes activos en el entorno penal y profesionales de la psicología, estamos atravesados por su fuerza impetuosa y sagaz. Los cuerpos travestidos de sujetos que se encuentran en el sistema penitenciario y estigmatizados como cuerpos perversos u obscenos por otros prisioneiros son juzgados por los placeres sentidos en la carne. Las travestis en el sistema penitenciario emergen como cuerpos ya juzgados y sometidos al castigo de la ley. Sin embargo, se abren nuevas formas de existir en un contexto diferente, que se rige por la institución penitenciaria posibilitando otras formas de sentir, pensar, desear, actuar y vivir. Presentamos aquí, de manera crítica, las conversaciones propuestas por la perspectiva Queer descritas en diversas fuentes bibliográficas que ofrecen oportunidades de nuevas preguntas y debates sobre la mirada para/ de la diferencia.

Palabras-Clave: Psicología; Travestis; Sistema Penitenciario.

Bárbara Cossettin Costa Beber Brunini, Wiliam Siqueira Peres, Rogério Amador de Melo 


\begin{abstract}
To present the Queer perspective is to act in a provocative and challenging way, especially when we, agents and professional psychologists who operate in the correctional environment, are transfixed by its impetuous and sagacious power. Transvestite bodies of subjects convicted in the prison system, who are stigmatized as wicked or obscene bodies by the other imprisoned bodies, and who are judged on the basis of their sensual pleasures. Transvestites in the correctional system appear as bodies that are already condemned and subject to the penalties of law. However, they find new ways to exist in a different context, which is ruled by the correctional institution, and provides different ways of feeling, thinking, wanting, acting and living. In this paper we present, in a critical way, discussions proposed under a Queer perspective, as described in various sources in the literature, providing opportunities for new questionings and debates about a difference-oriented vision.
\end{abstract}

Keywords: Psychology; Transvestites; Correctional System.

\title{
Introdução
}

A crítica teórica que sugerimos através deste ensaio apresenta-se enquanto diálogos propostos sobre a tríade corpos, desejos e prisões e geralmente remete as situações de violências e abusos sofridos por sujeitos submissos à instituição carcerária. Considerado um ambiente insalubre e hostil pelas suas ações de constrangimentos ou ferramentas corretivas, afastam dos corpos desejantes os prazeres e transcreve as violências em resposta às resistências destes corpos a repressão que lhes foram impostas. Corpos desejantes? Corpos desejados? Não, corpos relidos em suas funções e significados, tanto na dimensão filosófica como psicossocial e espacial regida por um tempo e espaço determinado mediante a pena a ser cumprida em resposta ao ato classificado como moralmente criminoso.

Essa incidência da prisão sobre os corpos é notória, igualmente identificável é a presença de suas formas de poder e aparatos discursivos que induzem certa impressão de posse sobre corpos condenados, desrespeitando suas reivindicações e utilizando de forças coercivas para adestrá-los e puni-los, domesticá-los e torná-los dóceis, harmoniosos à convivência social. Estes corpos já julgados e passíveis ao castigo da lei reinauguram novas formas de existir em um mundo diferente, agora regido pela instituição prisional, possibilitando outras formas de sentir, pensar, desejar, agir e vivê-los.

A procura destes prazeres ou corpos de prazeres ditos enquanto proibidos, é apresentada a Teoria Queer, hoje defendida não como teoria, já que se findaria no termo, mas uma perspectiva a qual emerge em conflito com os espaços discursivos que produzem a normatização das sexualidades, das raças, dos gêneros e das classes. Como apresentada por Guacira Lopes Louro, a perspectiva Queer "(...) incitam a jogar com suas ideias" (2004, p. 7), a pensar a partir do olhar estranho sobre uma nova gama de conceitos ou categorias ainda não pensados e, então, utilizando a expressão de Judith Butler, desestabiliza, transgride e confunde qualquer coerência compulsória, mesmo porque, quando analisado enquanto adjetivo, o termo Queer se traduz a expressões homofóbicas; no contexto anglo-saxão seria traduzida como

Bárbara Cossettin Costa Beber Brunini, Wiliam Siqueira Peres, Rogério Amador de Melo 
estranho, esquisito e Louro (2004) sugere o uso do termo enquanto verbo: estranhar, "(...) desconfiar do que está posto de mau jeito o que está posto; colocar em situação embaraçosa o que há de estável” (LOURO, 2004, p. 64).

Ao apresentar a perspectiva Queer como norteadora de nossas construções críticas, tomamos este estudo como movimento provocativo e, para nós, um tanto desafiador, mesmo porque pertencemos ao elenco de agentes atuantes em ambiente penal enquanto profissionais psi em uma Comarca do interior do estado do Paraná. Assim, a escrita deste trabalho se resume em nossos achados bibliográficos sobre os movimentos das travestis de transformarem seus corpos em corpos desejados por outros dentro da prisão e de qual forma constroem modos diferentes de relação com pessoas, com as situações de violências nos corpos, com os corpos desejantes e como os seus próprios desejos e prazeres. Nossa intenção foi apresentar, de modo crítico e instigador, conversações propostas pela perspectiva Queer, descritas em diversas fontes bibliográficas, oportunizando novos questionamentos e debates sobre o olhar pela/da diferença.

\section{O corpo abjeto, mas de desejo em cárcere}

Graciliano Ramos, em sua obra Memórias de um Cárcere I, nos faz refletir sobre a busca de liberdade dos corpos, quando nos encontramos sem qualquer tipo de cárcere: "Liberdade completa ninguém desfruta: começamos oprimidos pela sintaxe e acabamos as voltas com a Delegacia de Ordem Política e Social, mas, nos estritos limites a que nos coagem a gramática e a lei, ainda nos podemos mexer" (1992, p. 34). Assim, as travestis, longe da possibilidade de apresentar-se vestida de Chanel (Gabrielle Bonheur Chanel, mais conhecida como Coco Chanel, importante estilista francesa, influência mundial da moda), ou repaginadas por Pitanguy (Ivo Hélcio Jardim de Campos Pitanguy, considerado o mais renomado cirurgião plástico do Brasil), surgem enquanto corpos desejados em ambiente prisional e negociam suas formas de prazer dentro da liberdade que conseguem instituir neste local.

A conduta imposta dentro do presídio e o aprendizado de uma nova experiência nos corpos são marcados imediatamente pela força opressora da lei, todavia, as vozes que estes se permitem ouvir podem se apresentar como arbitrárias ao castigo ou ao quadro de sofrimentos e humilhação, ressignificando o ato e devolvendo aos corpos experimentações traduzidas como formas de prazer. Inserem, assim, novos registros de prazeres advindos de modos de subjetivação que desafiam o sistema ao qual foi submetido e ressignifica o estigma que reduz o sexo destinado à travesti em cadeia como apenas uma punição. Kiffer (2006) escreve sobre estas vozes do corpo: "a memória do corpo assume (...) vozes contraditórias. Uma propaga a lei, a outra pretende dispersá-la, pulverizá-la, secretá-la" (2006, p. 268). E, ainda sobre esta forma de se pronunciar, podemos citar a escrita de Michel de Certeau (1994) sobre as prisões do corpo: "não há direito que não se escreva sobre os corpos. Ele domina o corpo. A própria ideia de um indivíduo isolável do grupo se instaurou com a necessidade, sentida pela justiça penal, de corpos que devem ser marcados por um castigo" (Certeau, 1994, p. 231).

Mas, mesmo a instituição penal possui suas brechas e arestas por onde os

Bárbara Cossettin Costa Beber Brunini, Wiliam Siqueira Peres, Rogério Amador de Melo 
corpos realizam seus passeios e seus encontros, promovendo o empoderamento destas vozes desejantes, demonstrando a precariedade da justiça e sua insuficiência quando se declara frente a esta percepção de vidas e desejos dissidentes da norma.

"Precisamos viver, embora não seja certo que a nossa vida represente qualquer utilidade. Procuramos aguentar-nos de uma ou outra maneira, adquirimos hábitos novos, juízo diverso do que nos orientava lá fora (...)" (RAMOS, 1994, p. 170), brilhante escrita de Graciliano Ramos da qual nos utilizamos para realizar um paralelo com o desejo dos sujeitos, sem cumprimento de suas penas. Os corpos de desejos mapeados pelo funcionamento do corpo político carcerário são ridicularizados em seus trejeitos ou suas marcas, é fragilizado pelos castigos higienistas, impregnados pela moral e pela força bruta de seus agentes, degradando e martirizando suas histórias em prol da disciplina penal.

Quando subordinado a estes mecanismos de poder se tornam, também, os corpos do discurso e se refaz nas relações intramuros da prisão por meio dos conflitos implicados pelas relações de poder, já que aquilo que se transforma é especifico de uma determinada sociedade a qual é igualmente atravessada pelos corpos em mutação, todavia, ainda capturado pelo terrorismo de governo da normatização. Pacheco (2009) escreve sobre esta governabilidade do corpo: "governar o corpo passou a ser condição para governar a sociedade, administrar os afetos e domar as emoções" (2009, p. 231), e ainda lembra Foucault quando referencia o estudioso ao destacar: "essa colocação do sexo em discurso, segundo Foucault, verifica-se através da vontade de saber que gera, por sua vez, produção de saber e, consequentemente, produção de poder que se exercem através da necessidade de regular o sexo por meio de discursos úteis (...)" (PACHECO, 2009, p. 230).

Mesmo na ausência de Chanel ou Pitanguy, o desejo da construção estética corporal ocorre também em ambiente prisional. A silhueta feminina, a roupagem provocativa, a conduta insinuosa são ferramentas usadas por alguns considerados como convidativas à violência ou ao abuso sexual, mas, e quando este corpo sente prazer neste ato? Quando é resistente a qualquer tipo de racionalização do prazer sexual? Quando este corpo é Queer? A linha íngreme que separara a exclusão da relação, a dor do prazer, o mérito do castigo, desaparece diante da perspectiva Queer. As travestis, até nesta instituição que estamos discorrendo, se identificam com a imagem feminina, desejam a parafernália de adereços e gozam da presença da estética corporal transformada que lhes permite situar-se dentro da condição de bem-estar biopsicossocial desejável.

\section{A Perspectiva Queer: Atravessando os Discursos da Normatividade}

A ótica dos corpos sempre violentados pode ser revertida quando pensado nos corpos cedidos aos gozos intensos, aos seus e aos dos outros, recebendo status emancipatórios referenciados nos contextos onde estão inseridos. Apresenta-se aqui, também, a perspectiva Queer, um olhar sobre os corpos desconhecidos e, nem por isso, isentos de prazer, de novas roupagens e expressões de sexualidades e de gêneros. Peres (2008) cita Foucault quando

Bárbara Cossettin Costa Beber Brunini, Wiliam Siqueira Peres, Rogério Amador de Melo 
apresenta este corpo que falamos:

(...) podemos cartografar as múltiplas linhas de sua tessitura que fazem do corpo da travesti a expressão de uma multiplicidade que ora expressam devires de singularidades potentes e criativas, ora reproduzem valores, modelos discursivos repetitivos e normatizados pelas instancia regulatórias e disciplinadoras do biopoder" (PERES, 2008, p. 2).

Esta forma impensável socialmente de corpo e de prazer, bem como a estranheza provocada pela sua presença, contenta os binarismos em diferentes dimensões éticas de classes, raças, sexos e de gêneros. A teoria Queer, de acordo com Louro (2004), escapa a qualquer movimento classificatório, já que não é pretensão normalizar estes corpos ditos estranhos "(...) Queer representa claramente a diferença que quer ser assimilada ou tolerada" (LOURO, 2004, p. 38), opera via Judith Butler quando relata estes movimentos: “(...) dar-se conta das disputas, das negociações e dos conflitos constituídos das posições que os sujeitos ocupam" (2004, p. 49) e lembra que o termo significa sair do registro da identidade, não com o intuito de pensar na diferença, mas para apresentar o impensável e sair da mesmice classificatória que habitualmente é sentida como insuportável.

Para continuarmos a falar em sexos e corpos desejados das travestis, precisamos pontuar questões relativas às homossexualidades e as homofobias, e, por extensão, as transfobias, para tanto, nos paramentamos da escrita de Sedgwick (2007) ao descrever um pouco sobre a história da homossexualidade desde o final do século XIX, quando aponta que:

(...) na Europa e nos EUA, foi impulsionada pela relação distintivamente indicativa entre homossexual e mapeamentos mais amplos do segredo e da revelação, do privado e do público, que eram e são criticamente problemáticos para as estruturas econômicas, sexuais e de gênero da cultura heterossexista como um todo (SEDGWICK, 2007, p. 26).

Sedgwick (2007) nomeia o armário como a estrutura de opressão gay do século XX e lembra que, atualmente, a expressão "sair do armário" vem sendo utilizada para o "cruzamento e recruzamento de quase todas as linhas de representação politicamente carregadas (...)" (2007, p. 26) e provoca quando afirma que "para qualquer questão moderna de sexualidade, o par conhecimento/ignorância é mais do que simples parte de uma cadeia metonímica de tais binarismos" (2007, p. 29). Este par conhecimento/ignorância é ainda mais frequente quando falamos de sexo na cadeia masculina, já que o homem, varão, heterossexual que cumpre pena por determinado delito, tem dificuldades em falar do prazer sentido no corpo cedido, e avalia seu gesto como violência ou agressão, punição ou humilhação às travestis, ali apenas um corpo para seu deleite jamais reconhecido como desejado, até porque comprometeria sua tão comprovada heterossexualidade,

Bárbara Cossettin Costa Beber Brunini, Wiliam Siqueira Peres, Rogério Amador de Melo 
sua posição ativa, sua masculinidade diante de seus pares também homens, masculinos, machos. Não conseguimos nos desligar da obra de Sedgwick (2007) neste discurso machista, principalmente quando ela escreve sobre a angústia da "saída do armário", pois:

(...) ela pode trazer a revelação de um desconhecimento poderoso como um ato de desconhecer, não como o vácuo ou o vazio que ele finge ser, mas como espaço epistemológico pesado, ocupado, consequente" (2007, p. 35); “(...) sabemos muito bem quanto limitada é a influência que uma revelação individual pode exercer sobre opressões em escala coletiva e institucionalmente corporificadas (SEDGWICK, 2007, p. 36).

Para desnaturalizar o já cristalizado e transpassar os conceitos das regras e normas, utilizamos deste movimento nascido nas ruas que provocava os padrões de imposição e posturas disciplinares impostas socialmente e que promovem um atraso social e cultural sobre a necessidade de rever posições, um movimento considerado político e emancipatório, no qual a intencionalidade de problematizar situações contemporâneas reflete um prisma social e histórico de corpos tomados como não existentes, estranhados ou patologizados, resultantes da construção de pareceres que levam os sujeitos a pensar nos estereótipos carregados de carga semântica significativa: a perspectiva Queer. O posicionamento Queer pensa em estratégias de fuga para movimentos de transe desta sociedade dotada e limitada pela lógica binária e conceitual. A possibilidade de provocar a transitoriedade e atravessar estes conceitos capturados permite ir além do conceito, facilita experimentações, possibilita o movimento de alargar o mundo onde estamos inseridos e rever processos reducionistas de subjetivação institucionalizados.

A teoria Queer se recusa a enumerar, classificar ou dissecar as sexualidades disparatadas, antes se propõe a evidenciar os processos invisíveis que atribuem à perspectiva da normalidade, identificada como a própria razão, o poder de instituir esta designação-julgamento (MISKOLCI \& SIMÕES, 2007, p. 10).

Os processos de subjetivação atuam em carceragem como dispositivos disciplinares e totalizantes promovidos por regimes de verdades reforçando a ideia reducionista do ser humano a um sistema biológico ou a um funcionamento psíquico, o que por sua vez se aproxima e reforça as proposições feitas por Beatriz Preciado (2010), quando denuncia a tendência de sermos levados a acreditar na existência de um único corpo, um único sexo, um único gênero. Em resposta a determinação regulatória do biopoder, surge a prisão como um sistema específico que atua não só sobre o crime, mas, principalmente, sobre os corpos, seus prazeres e sobre políticas de desejos e de afetos. Mas, por outras vias, quando as resistências se processam diante das imposições do poder, outras subjetivações entram em ação e nos permitem falarmos em subjetivações criativas e subversivas que se aproximam das

Bárbara Cossettin Costa Beber Brunini, Wiliam Siqueira Peres, Rogério Amador de Melo 
expressões das estilísticas das existências e inventam novos modos de existencialização.

Judith Butler (2003) chamou este sistema regulatório e disciplinar de sistema sexo/gênero/desejo/práticas sexuais, os quais, segundo a escritora, seriam mantidos a partir de relações de coerência e continuidade, apresentando que, se o sujeito nasce macho, será necessariamente do gênero masculino e seu desejo será heterossexual com sua prática ativa; já quando nasce fêmea, seu gênero será firmado como feminino para que seu desejo seja heterossexual e suas práticas passivas, resultado este predito pelos dispositivos da heteronormatividade e do falocentrismo, bem como de seus padrões de controle na produção de sujeitos dóceis e disciplinados, os quais reproduzirão as ordens previamente ditadas, as quais limitam ou impedem processos emancipatórios psicossociais, mantendo as normas higienistas e universais, classificatórias e reducionistas, logo, de reducionismos e fixações de identidades naturalizadas, acabadas e totais. Para Butler (2003), a naturalização do sexo e do gênero é resposta do efeito de reprodução do modelo heteronormativo pela qual os sujeitos são capturados pelas ações e imposições do poder exercido por agentes políticos que fabricam o exercício da conduta esperado pelas tecnologias políticas, morais e cristãs.

Um modelo regido basicamente pelo sistema linear sexo/gênero/desejo, o qual marca a generificação do feminino no corpo de fêmeas com o desejo voltado ao corpo do macho e vice-versa, generificação do masculino no corpo macho possuidor de orientação erótica para corpos femininos, denotando o que a teoria foucaultiana já nos mostrava, quando afirma que este sistema é uma potente ferramenta do biopoder que se apresenta como estratégia para desenvolver bem estar, revelando uma ordem de sustentar o próprio poder, responsável pela disciplina dos corpos e regulação dos prazeres enquanto estratégia que se faz valer em qualquer instituição, seja a escola, a família, a sociedade ou a prisão, convalidando sua força através dos discursos que perpetuam a heteronormatividade como única e obrigatória.

Assim, onde houver dissidência da heteronormatividade, haverá a ação do biopoder na tentativa de interdição, regulação, controle, invisibilização, segregação, exclusão, estigmatização, destruição, etc. (PERES \& TOLEDO, 2011, p. 265).

Michel Foucault foi um dos principais disparadores dos estudos Queer quando apresentou em sua obra A História da Sexualidade I: Vontade de Saber a sexualidade enquanto dispositivo histórico de poder, desenvolvido na cultura ocidental, sendo o sexo um sistema de utilidade e regulação social. Nesta perspectiva:

A sexualidade é o nome que se pode dar a um dispositivo histórico: não à realidade subterrânea que se apreende com dificuldade, mas a grande rede da superfície em que a estimulação dos corpos, a intensificação dos prazeres, a incitação dos discursos, a formação dos conhecimentos, o reforço dos controles e das resistências encadeiam-

Bárbara Cossettin Costa Beber Brunini, Wiliam Siqueira Peres, Rogério Amador de Melo 
se uns aos outros, segundo algumas grandes estratégias de saber e de poder (FOUCAULT, 2005, p. 100).

Os diálogos sobre a ordem social do presente, a qual moveria o controle dos sujeitos, é então denominada de heteronormatividade e expressa expectativas, demandas e obrigações sociais que classificam a heterossexualidade como natural, sendo conceituada como um conjunto de prescrições que fundamentam e controlam estes processos sociais num dispositivo histórico da sexualidade. Aqueles sujeitos e aquelas sujeitas que fogem as regras destes dispositivos seriam, então, classificados como marginais, excêntricos, anormais, pecadores e pecadoras, criminosas e criminosos, desviantes, diferentes, agressores, Queer.

Sedgwick (2007) desenvolve um estudo clássico sobre estes sujeitos sem alternativas no passado e nem localização no presente, cujos futuros são incertos, o que demonstra o paradoxo de presença ou ser invisível, de voz fraca ou mudez total, de aceitação ou exclusão e o denomina de "epistemologia do armário", e sua escrita amplia nossa questão sobre o reconhecimento dos prazeres pelos corpos das travestis, quando nos traz que:

O aparente deslocamento da expressão "sair do armário" de sua origem gay em seu uso recente pode sugerir que o tropo do armário está tão perto do centro de algumas preocupações modernas que poderia ser (ou de fato foi) esvaziado de sua histórica especificidade gay (SEDGWICK, 2007, p. 28).

E continua posteriormente: “(...) o desejo que representa a sexualidade em si e, portanto, o conhecimento sexual e o conhecimento em si, é um desejo pelo mesmo sexo" (SEDGWICK, 2007, p. 29). As resistências à aceitação dos corpos das travestis em ambiente prisional, por parte de outros detentos, possuem as amarras da grande influência da heteronormatividade em suas interfaces com os machismos, racismos e misoginias e se disfarçam sob os atos das violências ou da humilhação, mas é sabido que os prazeres se encontram nestas relações, mesmo que silenciados e disfarçados ou oprimidos e escondidos, mas os corpos sentem prazer e provocam prazer, e em algum momento, de descontrole de si e de frenesi os corpos aceitam o sexo em suas mais ousadas manifestações e se desvestem das armaduras das normas, concordam em assumir-se desejados e desejantes, mesmo que por curtos espaços de tempo, pois:

(...) assumir-se é uma questão de intuição ou convicções que se cristalizam, que já estavam no ar por algum tempo e que já tinham estabelecido seus circuitos de força, de silencioso desprezo, de silenciosa chantagem, de silencioso deslumbramento, de silenciosa cumplicidade (SEDGWICK, 2007, p. 38).

Travestis: Os Corpos Desejantes do Cárcere

Bárbara Cossettin Costa Beber Brunini, Wiliam Siqueira Peres, Rogério Amador de Melo 
Diante do contexto prisional, alguns detentos reconhecem estes prazeres dissidentes, permitem a realização de seus desejos, mas, verbalizam justificando que o ato em si é um ato naquele ambiente, no caso, a prisão, e que depois que dali saírem não mais manterão relações homoafetivas, referenciando o que cita Saéz e Carrascosa (2011), do medo que estes homens possuem de perder suas identidades de varões e serem assimilados a uma mulher, perder sua identidade de homem, heterossexual, macho, masculino, viril, mantendo sua conduta homofóbica.

Neste movimento, Eve Sedgwick (2007) fortalece a afirmativa dos autores quando afirma que "o duplo potencial de prejuízo no caso da revelação gay (...) resulta em parte do fato que a identidade erótica da pessoa que assiste à revelação está provavelmente implicada na relação e, portanto, será perturbada por ela" (2007, p. 39). Assim, os corpos inventados para responder as demandas neste novo contexto social criam respostas aos processos de estigmatização que os marcam e regulam.

A respeito dos estigmas, Irving Goffman (1994) apresenta o que significam estes estigmas e nos leva a refletir sobre sua gênese em nossa sociedade, desde o conceito grego no qual se apresentava por meio dos sinais corporais, os quais indicavam características de extraordinário e desqualificador sobre os sujeitos e seus status morais, sinais estes feitos a fogo ou por cortes que denotavam que seus portadores eram escravos, criminosos, traidores e deveriam, entretanto, ser evitados. Na era Cristã, o estigma surge como sinal da graça divina ou em alusão médica a este conceito cristão referindo-se a sinais de determinados distúrbios físicos. Mas, notório é o conceito de estigma estabelecido pela sociedade moderna como forma de categorizar os indivíduos, baseando-se em pré-concepções de suas próprias expectativas normativas, imputando nos sujeitos, conforme Goffman (1994, p. 6), uma "identidade social virtual", diferenciando-se da chamada "identidade social real", que seria aquela que o sujeito na realidade se situar no mundo e prova possuir, dada sua autonominação e modos de expressões corporais.

"O termo estigma, portanto, será usado em referência a um atributo profundamente depreciativo, mas o que é preciso, na realidade, é uma linguagem de relações e não de atributos"(GOFFMAN, 1994, p. 6). De modo complementar, Richard Parker e Peter Aggleton (2001) nos falarão em processos de estigmatização que por si mesmos demarcam relações de poder, e, neste sentido, esses autores nos advertem:

(...) como conceito formal, a estigmatização capta mais uma relação de desvalorização do que um atributo fixo. (...) Estes processos [de estigmatização] só podem ser entendidos em relação a noções mais amplas de poder e dominação. Na nossa visão, o estigma desempenha um papel central na produção e na reprodução das relações de poder e de controle em todos os sistemas sociais. Faz com que alguns grupos sejam desvalorizados e que outros se sintam de alguma forma superiores. Em última análise, portanto, estamos falando de desigualdade social. Para confrontar e entender corretamente as questões de estigmatização e da discriminação (...) é necessário, 
portanto, que pensemos de maneira mais ampla sobre como alguns indivíduos e grupos vieram a se tornar socialmente excluídos, e sobre as forças que criam e reforçam a exclusão em diferentes ambientes (...) [Foucault] explicou como a produção social da diferença (...) está ligada aos regimes estabelecidos de conhecimento e poder. $\mathrm{O}$ assim chamado excêntrico é necessário para a definição do natural, o anormal é necessário para a definição da normalidade, e assim por diante [ou seja] enfatizou mais claramente a produção cultural da diferença a serviço do poder (...) e portanto, para o estabelecimento e manutenção da ordem social (PARKER \& AGGLETON, 2001, p. 11$13)$.

Seguindo essas problematizações Peres (2015, p. 76-77) acrescenta que:

Essa nova perspectiva de abordagem sobre os estigmas, tomados como produzidos nas relações sociais, favorecem uma ampliação conceitual e de análise sobre a realidade socioeconômica, cultural e política, pelas quais são produzidas as relações sociais e os valores e significados que são estabelecidos como modelos a serem seguidos. Seguindo essa lógica, estes autores ampliam a leitura realizado por Goffman sobre os estigmas, avançando no sentido de deixar de considerar o estigma como algo acabado e centrado no indivíduo, para pensar os estigmas como processos sociais que se estabelecem ao longo da vida das pessoas, como ações de poder que promovem desigualdades e exclusões, levando-nos a priorizar os mesmos como processos de estigmatização. No caso das travestis e seu universo existencial podemos perceber a presença de exclusões de toda ordem, de desigualdades que enfraquecem suas potencialidades e marginalizam suas práticas.

A(s) travesti(s), em sua nova roupagem, recebem igualmente e ainda com maior potência estes estigmas, mesmo porque os carrega desde muito cedo em qualquer outro espaço social de circulação pelo mundo, desde os espaços familiares, seguindo pelas relações de vizinhanças, nos espaços escolares, de acesso aos equipamentos de saúde, oportunidades restritas de trabalho, segurança pública e outras exclusões sociais, políticas e culturais. Seus efeitos são notórios em todas as épocas da vida das travestis, inicialmente marcada na esfera familiar quando expostas à rejeição ou abandono enfraquecendo princípios básicos de autoestima e autovalorização induzindo a procurar corpos próximos a sua forma de existir com o intuito de enfraquecer as forças discriminatórias e investindo na participação em atividades ou ações políticas e sociais para reverter os conceitos negativos adjetivados a si, afirmando as dificuldades de pontuar estas questões em uma sociedade já preparada para aceitar modos reducionistas de existências, desejos e práticas sexuais.

As experiências negativas de estigmatização e violências vividas são estendidas a todos os outros espaços sociais, inclusive na prisão. A ausência do

Bárbara Cossettin Costa Beber Brunini, Wiliam Siqueira Peres, Rogério Amador de Melo 
processo de empoderamento fortalece a discriminação e outras formas de violências, as quais, de acordo com Peres e Toledo (2011): "no caso das travestis, muitas são empurradas para a marginalidade, recorrendo à prostituição para sobreviver e compondo um imaginário que naturaliza a associação das travestis à prostituição (...)", e complementam atravessando conceitos já preconizados que “(...) travesti não é sinônimo de prostituição, e que se ocupa esse lugar no mundo isso ocorre em consequência das diversas desigualdades sociais, políticas, raciais, sexuais e de gênero que incidem sobre seus corpos" (PERES \& TOLEDO, 2011, p. 267).

No ambiente carcerário, as travestis tendem a se organizarem em resposta às necessidades de preservação moral e física, de produzir políticas de enfretamentos e de resistências aos poderes heteronormativos e falocêntricos demarcados nas prisões e evidenciados por Foucault, quando fala sobre os "encontros com o poder" que é explicado por Peres e Toledo ao afirmarem:

A partir desse encontro com o poder, e de resistência ao mesmo tempo, surgem novas possibilidades de existencialização, logo, de novas demandas psicossociais e políticas de emancipação de direitos a ter direitos, ou seja, de poder vivenciar sua condição de cidadania, visibilizando, assim, a emergência contemporânea de novos sujeitos (PERES \& TOLEDO, 2011, p. 268).

Parker e Aggleton (2001) conforme problematizações anteriores, também visualizam o papel central dos estigmas nas relações de poder e de controles e regulações biopolíticas e escrevem sobre seu resultado negativo para alguns e de valorização de outros, emergindo assim a desigualdade. Nesta perspectiva,

Estamos falando em desigualdade social para confrontar e entender corretamente as questões de estigmatização e da discriminação, (...) é necessário, portanto, que pensemos de maneira mais ampla sobre como alguns indivíduos e grupos vieram a se tornar socialmente excluídos, e sobre as forças que criam e reforçam a exclusão em diferentes ambientes (PARKER \& AGGLETON, 2001, p. 11-12).

Estamos, também, falando de desigualdades sociais, sexuais e de gêneros como reflexo e consequência das questões de estigmatização e discriminação e, por isso, é preciso pensar de modo mais amplo sobre as diversidades de sujeitos, grupos, desejos e práticas sexuais e sobre aqueles que vieram a se tornar excluídos socialmente, em nosso caso, não só os indivíduos em situação de privação de liberdade, já que estes sujeitos também são marcados pelos estigmas, mas das travestis encarceradas, que carregam além dos estigmas estabelecidos pelos comportamentos considerados pelo poder moral como delituosos, também os desejos e práticas sexuais subjugados como indesejados e não reconhecidos socialmente.

As identidades/expressões de gêneros, ou a materialização dos gêneros, "do gênero feminino sobre o corpo masculino" (PERES \& TOLEDO, 2011, p. 269), como no caso das travestis, remetem à construção de indivíduos

Bárbara Cossettin Costa Beber Brunini, Wiliam Siqueira Peres, Rogério Amador de Melo 
biologicamente masculinos que moldam seus corpos com características associadas ao feminino, sendo esta corporificação vista como apropriação de signos corporais e condutas políticas de gêneros, sexualidades e prazeres dissidentes por elas elaboradas, assumindo corpos desejados e mobilidades que lhes permitem transitar por diferentes esquemas e discursos já instituídos socialmente.

Borba e Orsternann (2008) citam Benedetti $(2000$; 2005) ao exporem "entre as travestis, a percepção de corpo e sua fabricação constituem sua identidade social, seu processo de fabricação como pessoa" (2008, p. 414) e continuam afirmando que "(...) esses processos de feminilização parecem enfatizar o fato de que a anatomia não é mais o destino da humanidade, já que pode ser facilmente manipulada por diferentes motivos" (p. 416). Assim, ao remodelarem seus corpos, estão incorporando suas ideologias sobre as feminilidades e masculinidades, bem como suas negociações de gêneros, fortalecendo, conforme os autores, sua polimorfia social (p. 427), pois:

As mudanças corporais elaboradas pelas travestis afirmam que identidade, especialmente identidade de gênero, é uma questão de estilo de vida e escolha, e não de essência (...) o corpo não pode ser considerado como meio passivo sobre o qual significados sociais são impostos (...) pelo contrário, considera o corpo como um participante ativo na construção de significados (BORBA \& ORSTERMANN, 2008, p. 416).

Distante dos corpos externos à carceragem, mantidos no ambiente social considerado harmonioso, onde desfilam os corpos perfumados, modificados e travestidos de marcas, rótulos e etiquetas, tão esmerados pelo social, estão demarcados na prisão as produções dadas aos corpos pelas travestis, os lugares ocupados e mantidos de prazeres que se vestem de características femininas, as quais se tornam atraentes diante dos seus adereços e indumentárias e lhes oferecem estéticas diferenciadas que lhes conferem estéticas e estilísticas da existência.

As fantasias, atrações e repulsas desses desejos dissidentes emergem intempestivamente no cárcere e se manifestam por acordos tratados entre os corpos conectados. Tais códigos combinados retiram as travestis da anterior posição de prostitutas e oferecem status aos corpos de desejos e não mais como corpos abjetos, como “(...) lugar ocupado por essas pessoas e os processes de estigmatização vividos que as expõe a situações de vulnerabilidades diversas e que se somam as estigmatização especificas de sexo, classe social, raça/etnia, orientação sexual, etc.” (PERES \&TOLEDO, 2011, p. 270).

Lembrada por Peres e Toledo (2011), Judith Butler (2002) oferece seu conceito de corpo abjeto (corpo tomado como não existente, patologizado, não humano) quando os apresenta enquanto agentes de resistências e de enfrentamentos do bio-poder e da heteronormatividade imposta como obrigatória e universal, empoderado e reivindicador, já que os outros sujeitos possuem dificuldades de identificá-las por estarem capturados pelas identidades normativas e reducionistas de sexo e gênero e se negam a

Bárbara Cossettin Costa Beber Brunini, Wiliam Siqueira Peres, Rogério Amador de Melo 
reconhecer os corpos das travestis como corpos de desejos e de, até mesmo, problematizar os seus próprios desejos e aponta que a repetição constante do mesmo acaba quando regimes de verdades e abominação de outros tipos de sociedades ou relacionamentos são enfrentados e dialogados. Neste sentido:

Quando o controle vem de fora, como é o caso das prisões, o sujeito quer libertar-se. Contudo, quando as normas vêm de dentro, porque foram interiorizadas (pela força do discurso, pelas repetibilidades, pelas performatizações normativas), já é o próprio sujeito que passa a governar a si mesmo (PINAFI; TOLEDO; SANTOS; PERES, 2011, p. 280).

Pinafi et al. (2011) fortalecem a leitura de Butler fazendo menção ao conceito da Pirâmide Erótica instituído por Rubin (1989), onde a autora apresenta uma escala hierárquica dos exercícios das práticas das sexualidades e modulações de seus prazeres com base nos padrões de sexo/gênero constituídos, os quais confirmam estes disparates das estigmatizações e das normatividades e colocam as travestis, as transexuais e homens trans, sadomasoquistas e pedófilos no seu patamar mais baixo, de abjeções e exclusões; todavia nos lembra de que:

O poder existe porque existem resistências e multiplicidades em nossos modos de subjetivação. Se todos fossem iguais não haveria necessidade de o poder ser exercido, não haveria sobre o que o poder agir, não haveria o que ser adequado às normas (PINAFI et al., 2011, p. 280).

As relações de sexos e desejos em ambientes carcerários se traduzem diante dos corpos desejados e desejantes, em nosso estudo, evidenciados pelos corpos das travestis e pelos sexos permitidos ou estabelecidos em seus acordos internos, contudo, trata-se de prazeres ainda interditados como é apresentado por Saéz e Carrascosa (2011):

(...) a penetração anal como sujeito passivo está no centro da linguagem, do discurso social, como o abjeto, o horrível, o mal, o pior. Todas estas expressões traduzem um valor primordial, unânime, generalizado: ser penetrado é algo indesejado, um castigo, uma tortura, um ato odioso, uma humilhação, algo doloroso, a perda da honra, é algo de onde jamais se poderia encontrar prazer (SAÉZ \& CARRASCOSA, 2011, p. 4).

Assim sendo, os autores defendem que estes corpos penetrados seriam equiparados ao corpo inferior da mulher, estipulado pelo machismo, e quando penetrado o homem seria rebaixado a este status diminuto, perdendo sua virilidade, pensamento este o qual fortalece a homofobia/transfobia e a discriminação, bem como a ignorância ou prepotência de acreditar que tem conhecimento sobre o desejo do outro. Por outro lado, podemos também

Bárbara Cossettin Costa Beber Brunini, Wiliam Siqueira Peres, Rogério Amador de Melo 
problematizar esses corpos e seus prazeres como ampliação dos universos de referências tidos, até então, evidenciando a emergência de novos sujeitos de direitos e, por conseguinte, novos modos de subjetivação.

Para inverter os regimes políticos heterocentrados, falocêntricos e heteronormativos, seria conveniente inverter estas lógicas reducionistas e atravessar os conceitos já instituídos e estáveis e de acordo com Saéz e Carrascosa (2011, p. 30): “(...) mostrar que se trata de um regime muito complexo que se constrói no dia a dia, um regime cuja elaboração participamos tod@s em maior ou menor medida".

Os corpos das travestis são corpos fluídos e dinâmicos que desafiam as normas e condutas fechadas do normativo e se organizam em seus desejos, práticas sexuais, prazeres e posições em suas relações. Parrini (2007) defende que, para entender o que se passa nas prisões, não se pode manter a polaridade feminino/masculino, homem/mulher, macho/fêmea, crendo que os gêneros correspondem à diferenciação de unidades discretas estabelecendo, assim, uma posição de "estar entre" (2007, p. 59-60), implodindo o terror sobre os gêneros, corpos e desejos nas prisões. Estas transgressões de fronteiras e ações subversivas de gêneros e sexualidades propostas são alguns dos elementos que fundamentam a perspectiva Queer, sustentada, também, pela teoria da performatividade traçada por Judith Butler (2002; 2003), utilizada para identificar os modos como estes corpos e sujeitos são produzidos, não em suas identidades sexuais hegemônicas, mas daqueles corpos definidos como estranhos, bizarros, Queer.

\section{Considerações Finais}

Estes corpos "desviantes" sugerem ampliações de possibilidades de ser, estar e circular no mundo, que dialogam com seus desejos e nos fazem pensar no antes impensável, desestabilizando, provocando incômodos frente nossas expectativas prontas, nos instigando a pensar e a problematizar sobre que corpos são estes? E então chegarmos a uma (im)possível conclusão: são corpos que resistem aos mecanismos de controles sociais regulatórios capazes de reinventar sexualidades e prazeres que respondem aos seus desejos e estilos de viver enquanto dispositivos próprios de seguranças, de gozos intempestivos como respostas atrevidas e ousadas à produção de condutas cristalizadas pelo biopoder, pela biopolítica e pelo biodireito os quais ignoram as diversidades positivadas e reconhecidas como corpos queerizados de sujeitos de direitos a ter direitos, logo, de acesso a cidadania enquanto participação política diante do Estado neoliberal e conservador.

"Daí, enfim, a inscrição da liberdade não apenas como direito dos sujeitos legalmente opostos ao poder, às usurpações, aos abusos do soberano ou do governo, mas da liberdade que se tornou um elemento indispensável à própria governamentalidade" (Foucault, 2008, p. 478). Um corpo livre, de Chanel, de Pitanguy, de prisão e de estigma, de violência, desejado por si mesmo.

As questões problematizadas neste artigo propõem contribuir com as discussões críticas aos regimes binários e universais que engessam os corpos e os reduzem a modelos de sexos, sexualidades, gêneros e prazeres que mostram a vida de modo ampliado em que as identidades tomadas como totalizadas

Bárbara Cossettin Costa Beber Brunini, Wiliam Siqueira Peres, Rogério Amador de Melo 
apenas produzem vidas precárias, fascistas e subordinadas, mas que podem ser resignificadas para que as diversidades eróticas sexuais sejam consideradas como multiplicidades que tomam a vida como valor maior e, neste sentido, respeitar a emergência e expressão das diferenças das diferenças. Que nenhuma identidade se fixe e se reduza como polícia e juíza das outras que diferem de si mesma.

\section{Referências}

BORBA, Rosermann, A. C. Gênero ilimitado: a construção discursiva da identidade travesti através da manipulação do sistema de gênero gramatical. Estudos Feministas, v. 16, n. 2, p. 409 - 432, 2008.

BUTLER, Judith. Cuerpos que importam: sobre los limites materiales y discursivos del sexo. Buenos Aires: Paidós, 2002.

BUTLER, Judith. Problemas de gênero: feminismo e subversão da identidade. Rio de Janeiro: Civilização Brasileira, 2003.

CERTEAU, Michel. Invenções do cotidiano I: artes do fazer. Petrópolis: Vozes, 1994.

FOUCAULT, Michel. Microfísica do poder. Rio de Janeiro: Graal, 1979.

FOUCAULT, Michel. História da Sexualidade I: a vontade de saber. São Paulo: Editora Martins Fontes, 1988.

FOUCAULT, Michel. Segurança, território, população. São Paulo: Martins Fontes, 2008.

FOUCAULT, Michel. Vigiar e Punir: nascimento da prisão. $35^{\mathrm{a}}$ ed. Petrópolis: Vozes, 2008.

GOFFMAN, Erving. Estigma: notas sobre a manipulação da identidade deteriorada. Rio de Janeiro: Zahar Editores, 1994.

KIFFER, Ana. Corpo, memória, cadeia: o que pode o corpo escrito? Alea, v. 8, n. 2, p. $263-280,2006$.

LOURO, Guacira Lopes. Um corpo estranho: ensaios sobre sexualidade e teoria queer. Belo Horizonte: Autêntica, 2004.

MISKOLCI, Richard; SIMÕES, J. A. Dossiê: sexualidades disparatadas. Cadernos Pagu, v. 28, p. 9 - 18, 2007.

PACHECO, Ana Laura. O corpo e os discursos: Dominação e segregação nos laços encarnados. A Peste, v. 1, n. 2, p. 225 - 244, 2009.

PARKER, Richard. Estigma, discriminação e AIDS. Associação Brasileira Interdisciplinar de AIDS - Cidadania e direitos, v. 1, Rio de Janeiro, 2001. 
PARRINI, Rodrigo. Panópticos y laberintos.Subjetivación y corporalidad em uma cárcel de hombres. Mexico: El Colegio de México, 2007.

PERES, Wiliam Siqueira. Travesti: corpo, cuidado de si e cidadania. Anais do Fazendo Gênero 8- Corpo, violência e Poder. Florianópolis, 2008.

PERES, Wiliam Siqueira; TOLEDO, L. G. Dissidências existênciais de gênero: resistências e enfrentamentos ao biopoder. Psicologia Política, v. 11, n. 22 , p. $261-277,2011$.

PERES, Wiliam Siqueira. Travestis brasileiras: dos estigmas à cidadania. Curitiba: Juruá, 2015.

PINAFI, Tânia; TOLEDO, L. G.; SANTOS, C. H.; PERES, Wiliam Siqueira. Tecnologias de gênero e as lógicas de aprisionamentos. Bagoas, n. 6, p. $267-$ 282, 2011.

RAMOS, Graciliano. Memórias de um cárcere I. Rio de Janeiro: Record, 1994.

RUBIN, Gayle. Reflexionando sobre el sexo: notas para uma teoría radical de La sexualidade. In: VANCE, C. Placer y peligro: explorando La sexualidadfemenina. Madrid: Talasa, 1989, p. $113-190$.

SAÉZ, Javier; CARRASCOSA, Sejo. Por elculo. Políticas anales. Epublibre, 2011.

SEDGWICK, Eve Kosofsky. Epistemologia del armário. Barcelona: Ediciones de La Tempestad, 1998.

SEDGWICK, Eve Kosofsky. A Epistemologia do armário. Cadernos Pagu, v. 28, p. 19 - 54, 2007. 